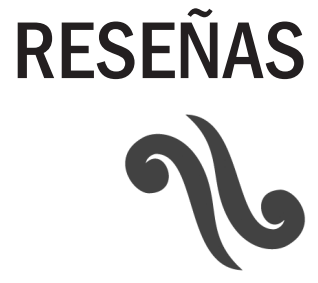





\title{
Vicisitudes de la cultura en México: lógica, metodología y argumentación*
}

\author{
Walter Beller Taboada
}

La divulgación de la ciencia es un campo consolidado que nos ayuda a comprender cómo se han conformado nuestro presente, nuestra vida institucional y las ideas que cobraron realidad gracias al empeño de hombres y mujeres que dedicaron su vida a la investigación y a la búsqueda de ideas creativas que innovaron el panorama internacional. El libro Lógica, metodología y teoría de la argumentación en México: 150 años de historia, desentraña las diversas corrientes de ideas que establecieron el currículo académico que, con algunos cambios, llega hasta nuestro tiempo: lo que hoy gozamos -o padecemos- tiene historia, y esa historia surgió de una voluntad de saber que modificó el sentido y la dirección de nuestros centros de educación superior.

La historia de la lógica en México ha tenido varias orientaciones, según las corrientes filosóficas que, en cada época, dieron el color y los matices sobre qué se debe entender por conocimiento, cómo hacer investigación científica, cómo razonar y cómo convencer a las audiencias. En las páginas del libro vemos desfilar las figuras de mexicanos que trascendieron las fronteras del país, cuyas obras se conocieron y consultaron en varias naciones de América Latina. Así, la labor del positivismo fue colocar, según su real saber y entender, las bases de la formación científica en México. El positivismo dio contenido a los planes y programas de la educación media superior. Con ello encontramos un repertorio de sorpresas; por ejemplo, que la elección del libro de texto de lógica para esos efectos propició una discusión en la Cámara de Diputados y otras polémicas que dejaron marcas de tinta en los periódicos nacionales. El libro triunfante se utilizó en la Cuba de aquel tiempo.

El neokantismo, una tendencia filosófica que buscó incorporar la historicidad del conocimiento (sobre todo ante el progreso incesante de todas las ciencias, lo

\footnotetext{
* Reseña de la obra de Walter Beller Taboada, Lógica, metodología y teoría de la argumentación en México: 150 años de historia, México, UAM-Xochimilco y Gedisa, 2020.
} 
que aconteció en forma vertiginosa durante las tres primeras décadas del siglo $\mathrm{XX}$ ), llegó al cenáculo del momento como una escuela antipositivista y con la era de la profesionalización de los maestros de filosofía. El neokantismo mantuvo un diálogo con el Estado e intentó alcanzar una hegemonía cultural en el momento de la acelerada modernización del país (como la refleja José Emilio Pacheco en Las batallas en el desierto).

La transformación de la revolución socialista alcanzó a México de diversas maneras. La generación de las bases de un intento de lógica dialéctica -es decir, una lógica que debía incorporar la contradicción y los procesos de cambio-, fue una auténtica novedad en su tiempo en el mundo y desde luego también en México. La orientación del materialismo dialéctico fue adoptada más por razones ideológicas que por motivaciones científicas. Sin embargo, incorporó una serie de aportaciones que por desgracia no fueron continuadas. Desde esa perspectiva se pensó que los métodos deductivo e inductivo no están delimitados de una manera rígida, ni en la historia del conocimiento ni en la metodología que se puede utilizar en el avance del saber. Además, el proyecto de lógica dialéctica utilizó por primera vez el álgebra de Boole, cuyo fundamento constituye las bases de los programas de computación.

Otra innovación de alcance internacional fue la lógica jurídica, concebida conforme las directrices de la época, es decir, empleando la teoría de conjuntos de Cantor. Esta innovación despertó el interés en varios países. Es una tendencia que no ha terminado de producir frutos en la esfera del Derecho y también de la moral y la ética.

Desde el inicio del siglo XX, la lógica en el mundo cobró un perfil definido por la lógica formal o matemática. En México, según se lee en Lógica, metodología y teoría de la argumentación..., la historia de la lógica matemática ha tenido variadas secuelas e importantes desarrollos. Pero no llega a tener las repercusiones que, en su momento, tuvieron las escuelas filosóficas que cobijaron a la lógica.

En la actualidad, resulta difícil hablar de "la lógica", porque en realidad es un dominio que tiene diversos alcances, sobre todo si se toma en cuenta lo que se conoce como "lógicas no clásicas". En este terreno se han incorporado investigaciones que tienden a cerrar la brecha entre el razonamiento común y corriente y el lenguaje lógico-formal. El caleidoscopio es interesante y en México se han abierto las puertas para la creatividad en lógica en sus diversas acepciones, un impulso que sigue dando frutos a partir del trabajo de investigadores como los que congrega la Academia Mexicana de Lógica.

Por otra parte, la argumentación ha ganado terreno, porque la comunicación exige que, cuando se razona, se ofrezcan no sólo premisas aceptables por quienes intervienen en un diálogo argumentativo sino que implica que éstos se sometan a reglas de corroboración para acatar los acuerdos, como lo planteó Habermas. Pues bien, en México ha sido una preocupación cada vez más definida el 
encontrar rutas de acceso a la argumentación y al despliegue de esquemas de y para la argumentación. En el nivel medio superior y superior, es cada vez más frecuente que se empleen recursos derivados de esta orientación de la vida social, donde se anudan instrumentos lingüísticos, semánticos y retóricos. De ahí la proliferación de obras que cubren buena parte del espectro de las publicaciones educativas.

En México, en la última década, los juicios orales, consecuencia de la reforma judicial en acto, han obligado a cambiar las estrategias de acusación y defensa en los medios jurídicos. De acuerdo con una tradición del siglo pasado, la lógica en el Derecho ha cobrado nuevos aires y hoy es parte significativa de la formación de los especialistas en las áreas jurídicas. La argumentación jurídica es una especialidad. También encontramos en el país una reciente variedad de publicaciones y explicaciones de los recursos que la lógica y la teoría de la argumentación ofrecen para una justicia más clara y expedita. Al menos esa es la tendencia. Los jóvenes abogados tienen que contar con esos instrumentos bajo la opción de "sí o sî".

Lógica, metodología y teoría de la argumentación en México: 150 años de historia, se ocupa de mostrar las muchas páginas que han servido para erigir instituciones, programas y actividades sociales y políticas, dando cuenta de una dinámica que si bien se muestra poderosa, no se conoce realmente en cuanto a los contextos que le dieron origen. Esta obra constituye una revisión bibliográfica extensa, salpicada de anécdotas que le dan colorido a una historia aún entre las paredes de las aulas universitarias, aunque su densidad histórica no se aprecie de manera directa. 



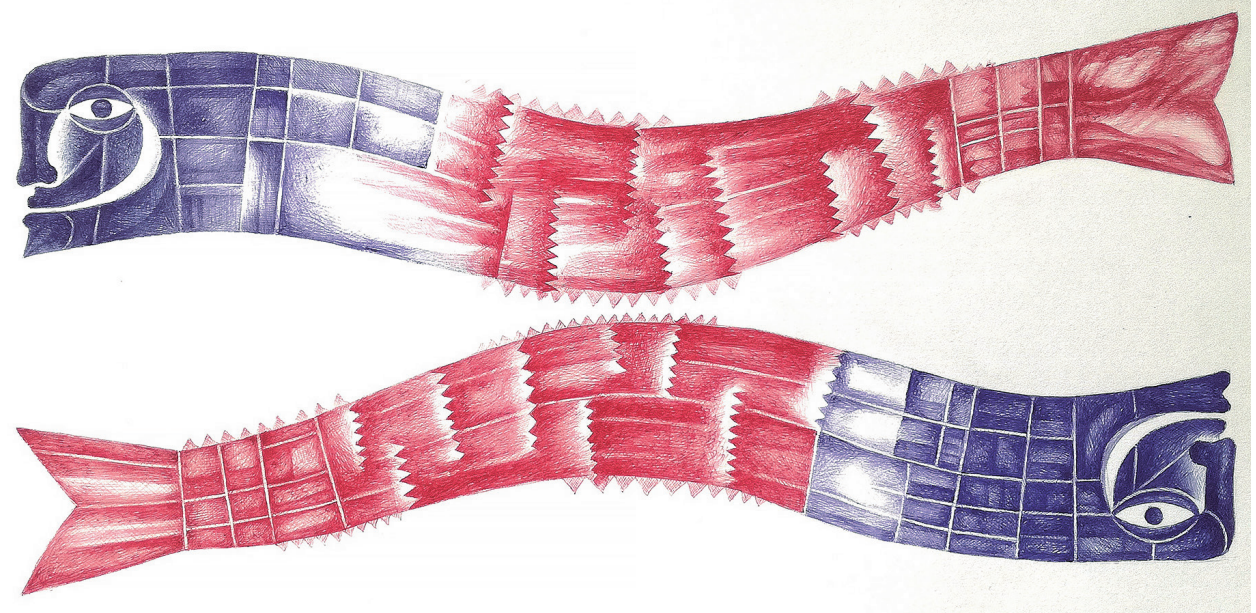

munta 
Ángel Vallarta | Sirenas 